\title{
TERRITORIO Y MÚSICA - UN DIÁLOGO, MÚLTIPLES ECOS: ENTRE TONALIDADES, SONORIDADES, ACÚSTICAS Y BULLICIOS DE LOS ESPACIOS ${ }^{1}$
}

\section{Agustín Arosteguy*}

Universidade de Buenos Aires/CONICET

Resumen: El artículo en cuestión pretende reflexionar sobre el diálogo que se establece entre música y territorio, englobando bajo la música todos los sonidos, ruidos, tonalidades y sonoridades que se pueden encontrar en los territorios, tanto urbanos como rurales, tanto concretos como simbólicos. Entonces, a partir de cuatro obras artísticas pertenecientes a diferentes artistas (el grupo Sincronicidad Astral, Pink Floyd, Floriano Romano y Atahualpa Yupanqui) y localizadas en distintos espacios y tiempos (Cerro Colorado 1998, Pompeya 1971, Río de Janeiro 2012 y Cerro Colorado 19381992), me interesa identificar las maneras en las cuales los territorios se hicieron presentes, concreta y simbólicamente, en los ruidos, los sonidos y las músicas de estas obras artísticas.

Palabras clave: Música y Territorio; Territorio simbólico y concreto; Arte sonoro; Música folclórica; Música psicodélica.

TERRITORY AND MUSIC - ONE DIALOGUE, MULTIPLE ECHOES: among tonalities, sonorities, acoustic and bustle of the spaces

Abstract: The article in question aims to reflect on the dialogue established between music and territory, encompassing under the music all the sounds, noises, tones and sonorities that can be found in places, both urban and rural, both concrete and symbolic. Then, from four artistic works belonging to different artists (the band Sincronicidad Astral, Pink Floyd, Floriano Romano and Atahualpa Yupanqui) and located in different spaces and times (Cerro Colorado 1998, Pompeii 1971, Rio de Janeiro 2012 and Cerro Colorado 1938 -1992), I am interested in identifying the ways in which the territories were present, concretely and symbolically, in the noises, sounds and music of these artistic works.

Keywords: Music and Territory; Symbolic and concrete territory; Sound art; Folk music; Psychedelic music.

\section{TERRITÓRIO E MÚSICA - UM DIÁLOGO, MÚLTIPLOS ECOS: entre tonalidades, sonoridades, acústicas e barulhos dos espaços}

Resumo: 0 artigo em questão pretende refletir sobre o diálogo que se estabelece entre a música e o território, abarcando sob a música todos os sons, ruídos, tons e sonoridades que podem ser encontrados nos territórios, tanto urbanos como rurais, tanto concretos como simbólicos. Então, a partir de quatro obras artísticas pertencentes a diferentes artistas (a banda Sincronicidad Astral, Pink Floyd, Floriano Romano e Atahualpa Yupanqui) e localizadas em diferentes espaços e tempos (Cerro Colorado 1998, Pompeya 1971, Rio de Janeiro 2012 e Cerro Colorado 1938 -1992), interessame identificar as formas como os territórios estiveram presentes, concreta e simbolicamente, nos ruídos, nos sons e nas músicas destas obras artísticas.

Palavras-chave: Música e Território; Território simbólica e concreto; Arte sonora; Música folclórica; Música psicodélica. 
Geografando la música

Definir o olhar com a linguagem do som, é mais fácil de afinar Olhar com escuta, é deixar a sonoridade saltitar, Geografando com solfejar. Conhecendo-se o som, muda-se o tom Para maior ou menor, na métrica certa, A música desperta, redefine o que é o olhar. Alessandro Dozena e Katia Agg (poema livre)

Como punto de partida me parece propicio, por un lado, mencionar las investigaciones sistematizadas por Leo Frobenius (1849-1917) sobre la relación entre espacio geográfico y música a partir de la ubicación espacial de los instrumentos musicales y la creación de zonas culturales. A través de ésta última, llegó a desarrollar la noción de Círculos Culturales (Kulturkreis²). Y por otro, las reflexiones impulsadas por el arqueólogo y geógrafo francés Georges de Gironcourt (1878-1960) sobre geografía musical como nuevo campo de estudios, considerando que la Geografía musical debía centrarse en las formas musicales desarrolladas a través del espacio y del tiempo, ya que mediante ellas podía trazarse la movilidad de poblaciones y sus orígenes (GIRONCOURT, 1939).

Lo que me gustaría destacar de los estudios de Frobenius y Gironcourt es que ambos ya vislumbraban trazos espaciales en la música, sea por el lugar en el cual los instrumentos fueron creados o por las cuestiones inmateriales, como ser las composiciones musicales. En este sentido, Lucas Panitz (2012) aclara que la principal diferencia entre estos dos pioneros fue "que mientras el primero reconstituía periodos históricos y prehistóricos a través de la cultura material, al segundo también le interesaban las formas no materiales como los ritmos, el canto y las danzas tradicionales" ( $s / p$, traducción del autor).

Este inicio tan promisorio de estudiar la música desde la disciplina geográfica tuvo una gran ausencia que se extendió hasta la década de 1990 cuando la música y las sonoridades volvieron a ocupar un lugar de relativa importancia. En este sentido, puedo destacar los trabajos de Susan J. Smith $(1994,1997)$ desde la Geografía Humanista, de Simon Frith $(1996,2003)$ desde la Sociomusicología y de George O. Carney $(1993,2003$, 2007), Lily Kong (1995) y Alessandro Dozena (2009, 2012, 2019a, 2019b) desde la Geografía de la Música.

Es en esta relación entre lo concreto y lo simbólico de la música en conexión con el territorio donde deseo situar el presente artículo. De esta manera, quiero explorar el diálogo entre música y territorio (DOZENA, 2019a,

2 Este concepto se basaba en principios difusionistas que consideraba que un número limitado de ciclos culturales se desarrollaban en diferentes momentos y en diferentes lugares y que todas las culturas, antiguas y modernas, fueron el resultado de la difusión de complejos culturales a partir de estos centros culturales (FROBENIUS, 1897) 2019b) a partir de cuatro obras artísticas pertenecientes a diferentes artistas y localizadas en distintos espacios y tiempos. Lo que me interesa identificar son las maneras en las cuales los territorios se hicieron presentes, concreta y simbólicamente, en los sonidos, ruidos y las músicas de estas obras artísticas. 0 en palabras de Alessandro Dozena:

[...] evidenciar el hecho de que los sonidos constituyen lenguajes espaciales, un medio capaz de comunicar ideas o sentimientos a partir de fuentes sonoras. Esta proposición considera que al oír música un individuo también "oye el territorio", en la medida en que las características musicales como la melodía, la armonía, las escalas y ritmos están relacionadas con el condicionamiento espacial específico (2019a, p. 32, traducción del autor).

A partir de la idea de Dozena, pretendo pensar cómo los sonidos, melodías, ritmos, tonalidades pueden identificarse con un espacio específico. Así las preguntas que intento responder son: ¿Existen sonidos en los lugares que sus habitantes identifiquen como propios? ¿Es posible pensar en una identidad sonora de una localidad, pueblo o ciudad? ¿Cómo se puede establecer una vinculación con el territorio más allá de los instrumentos musicales, o sea, mediante los sonidos, melodías, ritmos?

Teniendo en cuenta lo antedicho, los cuatro casos que utilizo para reflexionar sobre estos asuntos son: 1) el álbum Piedra de Plata del grupo Sincronicidad Astral que surgió de los experimentos para identificar la tonalidad de la localidad de Cerro Colorado (Argentina); 2) la película documental Live at Pompeii del cineasta Adrian Maben sobre el grupo Pink Floyd en la ciudad de Pompeya (Italia); 3) la performance sonora "A cidade sonora" idealizada por el artista carioca Floriano Romano; y 4) la relación que Atahualpa Yupanqui estableció con la localidad Cerro Colorado (Argentina) y reflejó en algunas de sus músicas. La decisión que llevó a elegirlos se basa en considerar que cada una de ellas permite reflexiones interesantes a ser realizadas dentro del diálogo entre territorio y música, ofreciendo diversos abordajes y perspectivas que sin lugar a dudas enriquecen esta temática. A continuación, presentamos cada uno de ellos.

\section{Cerro Colorado, 1998 - la tonalidad del paisaje}

Marcelo Vena, músico, pintor y escultor argentino, conoció Cerro Colorado en 1989, cuando tenía 20 años. Nacido y criado en Córdoba capital, desde temprano estuvo vinculado al rock. Por parte de su familia, el folclore siempre estuvo presente. Su abuelo era un gran 
cultor del folclore y vivió un tiempo en Salta. Era amigo de Balderrama y frequentaba las guitarreadas que se hacían en el legendario boliche ${ }^{3}$ todas las noches. Pero Marcelo se empezó a interesar por el folclore cuando fue a Cerro Colorado y conoció a Atahualpa Yupanqui o Don Ata, como a él le gusta llamarlo. Hasta ahí solo sabía que Yupanqui existía y había escuchado algunas canciones. El hecho de poder tratarlo le dio otra perspectiva de la persona y de la obra. Tuvo, además, la oportunidad de organizar todos los materiales que irían a formar parte del Centro Cultural, que en verdad eran objetos personales de Yupanqui. La propuesta del Centro era la de difundir las tradiciones criollas. Entonces, Yupanqui donó todos sus libros para crear una biblioteca en la cocina de la casa para que todos los habitantes del Cerro y los eventuales visitantes pudieran tener acceso. Ese lugar también funcionó como paraje para investigadores de la naturaleza y de la arquelogía. Allí podían instalarse e investigar por períodos de tiempo más prolongados.

El Centro Cultural que lleva como nombre Agua Escondida, está ubicado en un lugar privilegiado, rodeado de cerros, atravesado por un río y siguiendo un camino se llega a un peñasco que tiene una vista panorámica extraordinaria. Para llegar hasta el peñasco hay que pasar por un sendero, al cual Yupanqui llamó de Sendero El Silencio. Se dice que Yupanqui, a la vuelta de cada viaje, solía quedarse por ahí caminando y escuchando a la naturaleza, lejos de los sonidos y ruidos artificiales creados por el ser humano.

Cuando visité Cerro Colorado en julio de 2018, Marcelo me contó una anécdota que me llamó mucho la atención. A mediados de la década de 1990 en sus sucesivas y cada vez más frecuentes estadías en el Cerro, Marcelo comenzó a tocar y experimentar con los temas de Yupanqui, y también empezó a realizar grabaciones de sonidos ambientales y componer canciones que se le iban ocurriendo. Trataba, por un lado, de emular los estilos criollos de la región, como el gato y la chacarera y, por el otro, a través de afinadores y resonancias, jugaba con las notas en diferentes momentos del día, intentando imitar los sonidos de la naturaleza. Fue así que descubrió que la tonalidad, en general, de El Cerro Colorado estaba dentro de los tonos del re, fa sostenido, la mayor y re mayor. Cuenta que ese hecho fue toda una sorpresa para él y pudo comprobar que no era algo menor, ya que muchas de las canciones compuestas por Yupanqui

3 Peña Balderrama es un espacio que comenzó como un almacén en 1953 y se convirtió en un lugar de referencia dentro de la escena folclórica no solo salteña sino argentina. Ubicado en la ciudad de Salta y fundado por Juan, Daría y Celestino Balderrama, han pasado y tocado figuras del folclore y poetas como Juan Carlos Dávalos, Eduardo Falú, "Cuchi" Leguizamón, Manuel J. Castilla, Hugo Aparicio, Díaz Bavio, Jorge Cafrune, entre muchos otros. y por Pablo del Cerro ${ }^{4}$ sobre el Cerro estaban en esas tonalidades. Por ejemplo, los gatos "El pocas pulgas", "El rescoldeado", "El tulumbano", y las chacareras "La nadita" y "Chacarera de las piedras", están todas en afinaciones de re, están todas en re menor o en re mayor. Marcelo cree que no fue algo fortuito, sino que fue estudiado porque seguramente ese lugar debe haber resonado en esa tonalidad para que Yupanqui compusiese todas esas músicas en el mismo matiz tonal.

De esas experimentaciones personales, Marcelo grabó un casete al cual llamó de Cerreño. En Córdoba capital venía trabajando con otros músicos y otras bandas a las cuales les mostraba ese trabajo. Fue así que esas grabaciones llegaron hasta un productor argentino que trabajaba en el canal Discovery, que en ese momento estaba haciendo una investigación sobre sonidos para una universidad, y se interesó por el trabajo y contactó a Marcelo para realizar más grabaciones. Marcelo recuerda que: "vino con estudios móviles y se instaló en el Cerro, y estuvimos grabando muchas bases en la casa del indio Pachi y también trabajamos cosas que él trajo" (DIARIO DE CAMPO, 11/07/2018). Conversando sobre los sonidos ambientales y sobre la ambientación que le iban a dar a las canciones, surgió el tema de que Marcelo había estado 'jugando' con los sonidos de la naturaleza, viendo en qué tonos estaban y tratando de imitar las notas de, por ejemplo, el canto de los pájaros, del sonido del agua o de todo el "concierto que se da en la noche, que es una cantidad de sonidos de la naturaleza, de animalitos y bichitos que hacen su coro y tienen también una tonalidad propia" (Ídem).

Fue así que empezaron con los instrumentos y con la voz para conseguir emular y buscar la nota lo más exacta posible. Luego, utilizaron afinadores electrónicos e hicieron muchas tomas de sonidos ambientales, con la idea de grabar un disco y salir hacer presentaciones. Desafortunadamente el proyecto quedó trunco porque uno de los integrantes tuvo problemas familiares y de salud. Pero unos años atrás, Manuel Domínguez y Diego Caminos (los otros dos integrantes de Sincronicidad Astral), se contactaron con Marcelo y le propusieron que realizara el arte gráfico de un disco que ellos estaban haciendo. A su vez, ellos querían incluir uno de los temas que habían grabado juntos. Ese disco se llamó "Buscando huellas del olvido" y salió en 2014. Aunque Marcelo no participó mucho, él dice que se puede considerar como el primer disco de Sincronicidad Astral. A partir de la repercusión que tuvo ese trabajo y de las impresiones que causó en la gente, decidieron editar toda la música que habían hecho casi 20 años atrás,

4 Fue el seudónimo que utilizó la esposa de Atahualpa Yupanqui y eximia compositora, Antonietta Paule Pepin Fitzpatrick. 
pero que habían dejado sin finalizar. De esta forma, trabajaron durante un año masterizando el material y mejorando la calidad y agregaron un par de cosas nuevas intentando mantener la misma impronta. Fue así que nació el disco "Piedras de plata" (2016), el cual Marcelo describe como "un viaje sonoro que comienza en la primavera con la primera tormenta y transita todo el verano, los carnavales, después pasa por el invierno, la soledad, la muerte, hasta que vuelve a ser de nuevo primavera" (AUDIO WHATSAPP, 4/12/2018). Ese trabajo, está compuesto por 16 canciones y es el primer disco del grupo en el cual la base sonora está hecha con los sonidos grabados de la naturaleza. Sobre todo "Hombre puma" y "Don Indolfo", están acordes a la tonalidad del lugar y las demás canciones están mezcladas, en mayor o menor medida, con sonidos de pájaros, de agua de los ríos y de la atmósfera particular del Cerro Colorado.

En definitiva, lo que el grupo deseó transmitir con su trabajo fue la idea de que los lugares están habitados por espíritus, y en especial el espíritu de la tierra, que es la Pachamama. Entonces, ellos cada vez que graban piden permiso para hacer esas cosas y lo hacen siempre con la finalidad de compartir. Para ellos tiene mucho sentido estar conectados con la tierra, con la ancestralidad, con la humanidad. Ellos creen que todos los seres vivos participan en el proceso creativo: los árboles, los animales y los cuatro elementos (aire, fuego, agua y tierra). Por eso, ellos conciben la música como un ritual que los conecta con la luna, con el agua, con la noche y a su vez, tratan de evocar lo que les produce el efecto de la luna, el efecto del agua, o del viento. Es esto lo que procuran en cada canción.

\section{Pompeya, 1971 - la acústica del espacio}

Pasaron casi 1900 años para que la banda británica de rock psicodélico y progresivo, Pink Floyd, llegase a aquella ciudad cubierta, primero, por la lava y luego, por las cenizas del volcán Vesubio. Erupción que hizo de aquella ciudad, tal vez, el primer cementerio-ciudadmuseo a cielo abierto del mundo. El interés de la banda pasaba más por la experimentación acústica y no tanto arqueológica. Querían captar cómo sus músicas resonaban, repercutían y rebotaban en ese lugar que remetía a muerte, a tragedia y desolación. Fiel a su espíritu experimental que la caracterizó desde el comienzo, la banda sentía que esa oportunidad sería un antes y un después en la historia del grupo. Le querían tomar el pulso a esa ciudad mediante su música, sus sonidos, sus instrumentos. Esa ciudad que ya no era cualquier ciudad, era una ciudad con pasado de escombros, de escombros que alguna vez estuvieron revestidos de cenizas. Y ahí radicaba la curiosidad por conocer cuál sería el sonido que esas paredes, esquinas, curvas, casas, ventanas, puertas, tejados, chimeneas emitirían. ¿Serían amplificados o absorbidos? ¿Se expandirían más allá del oído humano o caerían, como peso muerto, al primer intento de captura? ¿Rebotarían en una peculiar carambola o se apagarían en el primer rebote? El director del documental, Adrian Maben, sería el encargado de registrar este momento. Él estaba consciente del contraste de grabar en vivo en una ciudad que había sido sepultada por 3 a 6 centímetros de cenizas volcánicas. Era una ciudad devenida en cementerio o un cementerio surgido de una ciudad y eso a Maben lo estimulaba porque de alguna manera filmar en el anfiteatro vacío de esa antigua ciudad, sin nada de público, era como "resuscitar el espíritu de Pompeya con sonido y color, imaginar que los fantasmas del pasado de alguna manera podrían regresar..." (FIELDER, 2016, s/p). Esa posibilidad estaba latente en el aire, era perceptible durante esos días de octubre que a pesar de ser oficialmente otoño hacía un calor atípico para la época.

$\mathrm{Si}$ bien el documental tiene 6 músicas ${ }^{5}$ ("Echoes" está dividida en dos partes), solo tres de ellas fueron grabadas en vivo en el antiguo anfiteatro romano. Las restantes fueron grabadas en diciembre del mismo año en un estudio en París. Casualidad o no, las 3 músicas en vivo remiten a una atmósfera densa y a la vez, sombría. Lo que da la impresión de que no fueron elegidas al azar. En principio, según manifestó el director, la selección de las músicas fue hecha por la propia banda, aunque él creía también interesante que tuviese material del nuevo álbum que iba a ser lanzado a finales de ese año, Meddle (1971), específicamente quería incluir "Careful with that axe, Eugene" y "A saucerful of secrets", ya que sentía que serían adecuadas para la película-documental (FIELDER, 2016). A continuación, analizaremos las estructuras y las letras de las 2 canciones que fueron grabadas en vivo, ya que "A sacerful of secrets" es instrumental:

- Echoes (duración 24:03 minutos): la canción comienza con un sonido de un objeto rebotando, haciendo ping, que fue creado como resultado de un experimento en las sesiones del disco Meddle, producido al amplificar un piano de cola tocado por Richard Wright. Después de varios pings, el efecto slide de la guitarra tocada por David Gilmour se une de manera gradual. Pasados unos minutos instrumentales, Gilmour y Wright empiezan a cantar juntos. Otro verso y coro siguen al primero y luego un solo de guitarra toca una progresión y alcanza

5 "Echoes, part 1" (Meddle, 1971), "Careful with the axe, Eugene" (Ummagumma, 1969), "A saucerful of secrets" (A saucerful of secrets, 1968), "One of these days" (Meddle, 1971), "Set the controls for the heart of the sun" (A saucerful of secrets 1968), "Mademoiselle Nobs" (performance en vivo de Seamus, Meddle, 1971) y "Echoes, part 2" (Meddle, 1971). 
el clímax al final de dos progresiones de coro. Seguido del clímax, comienza un pasaje de improvisión que se prolonga por algunos minutos. Durante la improvisación, Roger Waters toca el bajo mientras que el baterista, Nick Manson, toca 4/4 y Wright acompaña tocando un órgano Hammond. Gilmour, por su parte, toca varios solos de guitarra cortos, la mayoría distorsionados. Esos instantes dan una sensación de desolación que parece remitir a Pompeya después de la erupción. A los once minutos, la improvisación acaba dando lugar a un crescendo que imita el sonido del viento, creado por Waters utilizando el efecto de slide en su bajo enviando este sonido a través de una Binson Echorec, al cual se le suma un ruido de chillido agudo, creado por Gilmour al conectar sin querer un pedal wah-wah al revés. En el minuto quince, el ruido se desvanece y empieza a escucharse varios pings mientras los platillos de Mason van creciendo en intensidad y frecuencia. En ese momento, Gilmour toca notas apagadas para coincidir con las del bajo de Waters. Wright se suma con un solo de órgano que dura hasta el final de la sección. Ahí se produce un clímax musical donde Gilmour toca notas altas mientras que el resto de la banda toca notas bajas, haciendo resaltar aún más el sonido de su guitarra. El final del clímax instrumental conduce al tercer verso de la canción en la voz de Gilmour y Wright. La banda toca dos estructuras de coro y luego una progresión de verso silenciosa y repetida sirve de marco para el fin de la canción. En esta parte final, se escucha un segmento de sonido coral. Dicho sonido fue creado al colocar dos grabadoras en las esquinas opuestas de una habitación. Las cintas con los acordes principales se introdujeron en una grabadora y se reprodujeron mientras se grababan al mismo tiempo. La segunda grabadora estaba configurada para reproducir lo que se estaba grabando. Esto creó un retraso entre ambas grabadoras, lo que influyó de forma significativa en la estructura de los acordes y, al mismo tiempo, dio una sensación de eco húmedo ${ }^{6}$. Resulta muy interesante observar que la letra de esta canción, posee vestigios que remiten a Pompeya y a su tragedia, especialmente el siguiente fragmento:

Por encima del albatros

Se cuelga inmóvil en el aire.

Y muy por debajo de las olas ondulantes.

En laberintos de cuevas de coral.

El eco de un tiempo lejano.

Viene sollozando a través de la arena.

Y todo es verde y submarino (traducción del autor)
- A saucerful of secrets (duración 10:17 minutos): aunque algunas veces la canción aparezca como una sola, hay otras que está dividida en cuatro partes: 1) Something else (0:00-3:57); 2) Syncopated Pandemonium (3:577:04); 3) Storm Signal (7:04-8:38); Celestial Voices (8:3810:17). Roger Waters dijo una vez en una entrevista para la revista Rolling Stone que la canción trataba sobre una batalla y sus consecuencias. De esta manera, Something else representa la configuración de la batalla en la cual los instrumentos van apareciendo y organizándose en una especie de estructura u orden aparente, anunciando de alguna manera que lo que viene no será fácil ni agradable. Predominan los platillos tocados por Mason y Waters, y la guitarra de Gilmour crea efectos sonoros inquietantes. Los instrumentos, que a medida que avanza la canción se hacen menos reconocibles, crecen hasta el punto de conmoción o estallido que provoca Waters al golpear con mucha potencia los platillos; Syncopated Pandemonium, significa la batalla real. Aquí la presencia de la batería marca un ritmo más frenético mientras que los otros instrumentos (guitarra, platillos y piano) entran y salen creando una atmósfera de desorden y caos con la intención de reflejar la violencia y truculencia de las guerras. El momento álgido se alcanza cuando Waters golpea el gong de manera descontrolada contrastando visualmente con el sol que se pone mientras que los demás instrumentos lo acompañan en una carrera hacia el abismo; Storm Signal, hace alusión a los muertos después de la batalla. La canción entra en un momento sombrío creado por el órgano de Wright avisando que la guerra ya acabó. De a poco el resto de los instrumentos (guitarra, batería y bajo) se van sumando haciendo que el ritmo de la música sea cada vez más alto, tanto en intensidad como en velocidad, hasta llegar a un momento de redención que es Celestial Voices, que representa el luto por los muertos. Aquí predomina el órgano con notas más extensas y de sonidos más abiertos dando a entender un momento de reconciliación después de la virulencia de la batalla. La canción concluye con un coro de voces agudas que son acompañadas por las notas del órgano cada vez más prolongadas y abiertas ${ }^{7}$. Esta especie de ritual mortuorio que conforman estas cuatro partes, podría perfectamente ser para las 25 mil personas que se estima murieron por la erupción del volcán.

- One of these days (duración 5:45 minutos): el elemento predominante de la canción es un bajo tocado a través de una unidad de retardo (eco), configurada para producir repeticiones en tripletes de un cuarto de nota. El

7 Esta información fue obtenida y traducida por el autor en la enciclopedia abierta Wikipedia: https://en.wikipedia.org/wiki/A_Saucerful_of_Secrets_ (instrumental)\#cite_note-10. Acceso en: 18 dic. 2018
6 Esta información fue obtenida y traducida por el autor de la enciclopedia libre Wikipedia: https://en.wikipedia.org/wiki/Echoes_(Pink_Floyd_song). Acceso en: 18 dic. 2018. 
resultado son ecos agregados que producen el siguiente patrón: cuarta - octava - cuarta - octava. Por otro lado, los acentos distintivos del teclado están compuestos por tres componentes: un órgano Hammond en 'fade in', seguido de un "stab" compuesto por un segundo órgano Hammond con parada de percusión, y, por último, un sonido sobregrabado con un piano acústico alimentado por un parlante Leslie. La lírica amenazadora, una rara contribución vocal del baterista Nick Mason, se grabó a través de un modulador de anillo y se desaceleró para crear un efecto extraño ${ }^{8}$. Dicha frase, one of these days I'm going to cut you into little pieces (uno de estos días voy a cortarte en pequeños pedazos), parece una especie de premonición al revés o un déjà vu y, al mismo tiempo, parece corresponder a los restos encontrados por las excavaciones arqueológicas realizados en Pompeya durante el siglo XVIII.

\section{Río de Janeiro, 2012 - el bullicio de los lugares}

Toda ciudad posee su sonoridad, su ritmo, su cadencia. Esa, por lo menos, pareció ser la premisa sobre la cual el artista Floriano Romano partió para concebir su obra "A cidade sonora" (2012). Para ello, no solo se inspiró en su ciudad natal, Río de Janeiro, sino que buscó también en otras ciudades brasileñas, como Arraial da Ajuda y Cachoeira (BA), Vila de São Jorge (GO) y San Pablo, pasó por Buenos Aires y Nueva York, y transitó por las siguientes ciudades europeas: Vila Armação de Pera, Azores y Oporto (Portugal), París, Londres, Bergen, Amsterdam y Madrid. Sin embargo, a partir de la propuesta del artista carioca lo que queda claro es que ninguna ciudad por más pequeña que sea, puede estar ajena o exenta de sus sonidos. Más bien pareciera efectuar, en un movimiento digresor, amplificaciones sonoras que no mueren en el instante en que son producidas, sino que perviven (o cobran vida) en las personas, animales, árboles, autos, bicicletas, cordones, baldosas, canteros, postes de luz, semáforos, adoquines y todo lo que circula y habita en ella.

Esto queda en evidencia en las 20 cabinas telefónicas reproduciendo sin pausa y en simultáneo el sonido de diferentes ciudades del mundo o, mejor dicho, 20 recortes espacio-sonoros de tales ciudades. Recortes que son, al mismo tiempo, personales (el artista pidió a personas conocidas que le enviasen las grabaciones) y representativas de aquel lugar en el cual el sonido fue captado y grabado. Esa mistura de sonidos crea una amalgama en la cual cada uno de ellos posee una

8 Esta información fue obtenida y traducida por el autor de la enciclopedia abierta Wikipedia: https://en.wikipedia.org/wiki/One_of_These_Days_ (instrumental). Acceso en: 18 dic. 2018. historia, un conjunto de memorias y hasta afectos que se acumulan y entremezclan con la ciudad, con sus transeúntes y sus diversos componentes animados $\mathrm{e}$ inanimados. Así el propio artista explica:

Las 16 grabaciones sonoras de grandes metrópolis y aldeas, enviadas por artistas o no artistas, ayudaron a construir este paisaje, este rumor de una ciudad imaginaria que es la reunión del ruido de la calle, de la plaza, del subte, algo que las personas descartan durante el día y tratan como basura sonora. Aquí, intentamos imaginar cómo sería el espacio de esta ciudad sonora, pues él es construido en la imaginación de las personas, a partir de la riqueza de detalles que llegaron en las grabaciones, del registro de estos paseos por las ciudades, de estas caminadas sonoras (ROMANO, 2012, s/p, traducción del autor)

El artista reivindica aquí el caleidoscopio sonoro que es la ciudad y es en esa reivindicación que Romano propone descubrir las ciudades imaginarias ocultas 0 poco visibles y que paradójicamente son visibilizadas a través de sus sonidos, sus ruidos, sus acentos y también, en la ausencia de sus silencios (ESPINHO, 2012). Y es justo en esa ausencia donde radica el potencial de la obra, ya que pone de manifiesto la creciente pérdida de silencio que a lo largo de los años todas las ciudades, sin importar su porte, vienen teniendo. En última instancia, lo que el artista desea es que la instalación instigue al visitante $\mathrm{y} / \mathrm{u}$ oyente a escuchar la ciudad, a descubrir una ciudad hibrida, tanto poblada de imágenes como de sonidos, y también vivenciar cómo las múltiples territorialidades (HAESBAERT, 2005) son también caracterizadas por sonidos propios e intransferibles. De esta manera, Romano compone y recrea una suerte de versión sonora del libro Las ciudades invisibles de Ítalo Calvino (2003).

Cerro Colorado, 1938-1992 - la musicalidad del territorio

A pesar de las 1200 composiciones parece que Atahualpa Yupanqui no agotó del todo la mística que envuelve al ser humano con la tierra. Es que Yupanqui buscó mediante la música acceder a la etnografía sonora de los lugares que visitaba, pretendía comprender las grafías sonoras de esos espacios. Tal vez ese interés por el territorio haya sido estimulado por su estrecha relación con el nordeste argentino, región que recorrió y que conoció en profundidad. Desde temprano también se interesó por la lengua quecha. Tan fuerte fue su conexión que decidió cambiar su nombre de nacimiento, Héctor Roberto Chavero, por el seudónimo artístico de Atahualpa Yupanqui. En quechua Yupanki significa "el 
que viene de tierras lejanas para contar algo". Por un lado, el seudónimo trae implícito la cuestión del territorio y, por otro, la necesidad de contar/narrar que en este caso específico se concretiza mediante el canto. El origen del seudónimo se remonta a su adolescencia cuando tenía que caminar 15 kilómetros por día para tomar las clases de guitarra con el concertista Bautista Almirón. Otra frase que Yupanqui gustaba mucho de pronunciar siempre que tenía la oportunidad era "runa allpacamaska", que significa: el hombre es tierra que anda. Yupanqui en 1948 publicó un libro con el nombre de Tierra que anda, el cual contenía siete partituras, fragmentos de las letras de dichas canciones y tres textos. Entre esos textos había uno con el título de ¡Runa allpacamaska! y que transcribimos a continuación por resultar significativo para expresar lo que Yupanqui pensaba y sentía sobre la tierra en su relación estrecha con el ser humano:

Trajinando caminos abajeños, con raros soles y desconocidas lluvias, viene llegando al Plata la caravana india. Todos, y cada uno, alientan la suprema esperanza: ¡Sentir suya la tierra en que nacieron! ¡Mirar en paz, con ojos amigos y corazón sereno, las piedras milenarias y las arenas altas que guardan las huacas donde duermen los abuelos, donde vagan libremente los escasos rebaños de vicuñas y guanacos, donde florece el cebadal azul, donde se mece tímida la esbelta quínua, donde el pajonal hace nacer un canto, donde a veces la piedra deja un lugar para la buena siembra! Más que una conciencia de Patria, el indio tiene un instinto de Tierra. La magia de los libros y la historia general de la Nación, no llegó a penetrar en el pueblo andino. Las corrientes literarias, la información variada, la instrucción sistematizada, se extiende a lo largo del cajón de Humahuaca, siempre pegada a la cinta atrevida del ferrocarril. Allí sí que han de estar enterados, más o menos, de las cosas del mundo. Pero para el hombre de arriba, para el proletario de los altos valles, para el runa señor de las cumbres, no existe otra magia que la voz de los vientos, que el nubarrón indeciso, que el remolino inútil, que el río sorprendente y caprichoso, la noche larga y la vida gris. Alguna vez se unieron rebelados, el arriero, el labrador y el siete oficios. Cuando alguien del Sur compró tierras en Cerro Moreno, los kollas de Purmamarca supieron cómo apretaban los arriendos y los impuestos. Bajaron hasta Volcán, airados, en un desordenado malón de ponchos raídos y verdades $\sin$ amparo. Hubo prisiones, discusiones, rebencazos, pleititos con abogados románticos. Los líricos indigenistas hablaron de leyes nuevas y de reivindicaciones, y de flautas de caña, y de danzas nativas, y de colores, melenas y ushutas. Pero los purmamarqueños del Cerro Moreno tuvieron que volverse a sus cumbres, arrimarse a las piedras y aguantar el arriendo, y sufrir los embargos. $Y$ tuvieron que dejar sus predios indios, y bajar al cañaveral para juntar la platita que cada año debían entregar. Tal vez en esos días, desde cualquier esquina del altiplano, la sombra augusta de Tomás Catári les habrá dicho: “¡Yo me fui desde Potosí a Buenos Aires, a pie, en cuatro meses, a pedirle al virrey Vértiz un documento que ordenara la libertad de los indios del Alto Perú, en 1780! ¡Yo llegué a la gran aldea del Sur, hablando solamente el aimará y el quechua! Me dieron el documento; ¡volví al altiplano, y allí me metieron a la cárcel, rompieron los papeles, y al tiempo destrozaron mi cuerpo en los pedregales! ..." Runa Allpacamaska... "El hombre es tierra que anda". Los cobrizos mozos de Coranzulí, desde la puerta de Tolar Grande y las Salinas de Atacama, levantaron una vez el grito solitario. La voz se llenó de plomo, y el gran corazón del Ande manchó de sangre las azufreras y los medanales de Susques. ¡Lloró la tierra alta, desde Polvorilla a Casavindo, y un gran silencio se extendió por la Puna! Tal vez en esos días desde la meseta del Chañi Grande, la voz de Pilltipico les habrá dicho: "¡Yo organicé a los ocloyas, homahuacas y kollas para resistir el yugo español, respondiendo al reclamo de José Gabriel Condorkanqui, aquel Tupac Amarú tan nuestro como el aire! ¡Me aplaudieron al principio, y me persiguieron después, y un día me fusilaron en Simoca, un olvidado rincón del Tucumán! ..." El hombre es tierra que anda... Los ríos de Jujuy riegan las tierras de los hombres ricos. El Huasamayo, el Zapla, el Labayén, el Chisjra, el Río Grande... Nada sabe la tierra india de este viaje rumoroso y feliz de los ríos. Al nacer, la vertiente se lava los ojos con una nieve blanca, y los pastorcitos y las imillas aprenden allí la primera ronda, y el chango leñero sabe cómo es de buena la vida que ofrece un lloro de agua de trecho en trecho. Pero es "agüita, nomás..." Cuando de brinco en brinco, la corriente encuentra un cauce seguro y se lanza, más lenta, más densa, más "ella", entonces le llaman río. Y es entonces cuando el agua ya no sabe nada de la tierra india ni del hombre arribeño. A medida que el agua va ganando leguas en tierra abajeña, se va olvidando de los pobres. El río tiene a veces, la misma mala memoria de los gobiernos. El hombre es tierra que anda... Ahora viene la caravana india, trajinando caminos. No todos son kollas. Los hay de Ledesma, mestizos, criollos de cepa hispana, matacos, tobas algunos, otros de raíz calchaquí. Los kollas vienen a pie. El indio puneño, es el gran infante de América. La ushuta es calzado heroico, porque además de soportar al hombre, soporta también al gran silencio del hombre. Ciento cincuenta nativos caminan estas sendas abajeñas hacia la ciudad endiablada, hacia el laberinto de callejas y avenidas. Ellos, que vienen de lejos y de muy alto, entrarán en la ciudad de la urgencia, del ritmo rápido, en la ciudad donde todos hablan a la vez, y a gritos, en la ciudad donde muchísimos estudian, muchísimos trabajan, y muchísimos viven esperando... y esperando... Es para ellos un mundo nuevo. Andarán por estas calles porteñas, con su mirar asombrado, aunque bien disimulado. Cada uno de ellos trae la atmósfera de su pago nativo. Veremos el poncho de tres colores, que usan los quebradeños, tierra de arenas policromas, claveles chiquitos y aromados de 
aire antiguo. Veremos el poncho rojo y azul de "los del ramal", que usan los del lado de Ledesma, Pampichuelo, Calilegua, Oran y Fraile Pintado. Veremos también el poncho pardo, sin flecos ni dibujos, que usan los kollas de la Puna desolada. Cada cual trae la atmósfera de su paisaje. Las cholas lucirán sus polleras superpuestas, sus sombreritos redondos, su chacuña azul, su bata blanca, sus zarcillos de plata india, su collar de huayruros, su andar de llama grácil.

Son proletarios del Ande secular. Son brazos de la zafra, presas del paludismo. Son hombres que aman la montaña y la altipampa, y no quieren dejarla. Son hombres que quieren tierra ancha y suya, para sembrarla, regarla, hacerla provechosa para la familia y para la Nación. Son hombres que vienen de lejos y de muy arriba, para pedir un pedazo de suelo argentino, un tractor, una bolsa de semillas, una verdad criolla y un sentido primordial: El de vivir como trabajadores del campo argentino, y no como siete oficios, como una cosa sin sensibilidad y sin destino. Esta marcha tiene también una deserción dolorosa. Un hombre cayó en el camino: el indio Romero. Tenía 60 años y muchos achaques. Era peón de surco, peón de quebrachales, limpiador de acequias, engrasador de carros. ¡Era... Siete oficios!... Lo apretó el invierno de la tierra abajeña, allá, cerca de Frías, en el camino... Lo velaron en una aldea santiagueña, como se vela a un indio: golpeando una caja, diciendo una copla, rezando en criolloquichuista un mensaje cualquiera a cualquier Santo. $Y$ también, pensando mucho, y sintiendo bien adentro, cómo duele el camino cuando la sombra muerde los colores del poncho y la esperanza del alma... Allá, en el camposanto de Frías, ha quedado una cruz de algarrobo, sobre el sueño del indio Romero. Tal vez los canchos y los chalchaleros, tal vez la dulce torcaza y las reinamoras le traerán a la hora de la siesta las cosas eternas del aire provinciano, en esa trova liviana y agreste que puebla la selva. ¡Mi corazón te piensa con sabor de vidala, paisano de mi tierra! El hombre, es tierra que anda... ¡Runa, allpacamaska! (YUPANQUI, 1948).

De todas las ciudades y países por los cuales Yupanqui anduvo, Cerro Colorado ocupó un lugar peculiar en su vida. Arribó a dicha localidad en 1938 y no consiguió salir más. Llegó por casualidad acompañando un amigo, Ernesto Gómez Molina, que con un camión y un proyector iban de pueblo en pueblo haciendo de cine ambulante. Proyectaban películas de William Hart, Richard Dix y otros cowboys de la época. Una sábana servía de pantalla. Del lado de leer se cobraba 20 centavos, del otro, 10. Una vez terminada la película se retiraba la sábana atada a dos árboles y Atahualpa subía a la caja del camión para dar un concierto de zambas, chacareras y gatos para el pueblo que allí se había reunido. Así se ganaban la vida estos dos amigos. Y fue de esta manera que llegó a Cerro Colorado, el lugar que sería su "querencia" y la comarca de su último silencio. Fue esta localidad que Yupanqui descubrió como una región imaginaria, otorgándole características que estaban más allá de lo que se veía a primera vista, de lo que la realidad física manifestaba. En este sentido, Cerro Colorado nunca más volvió a ser el mismo. Atahualpa le imprimió un aura mágica que perdurará por los tiempos de los tiempos y que inmortalizó en canciones como "Córdoba norte”, "La colorada", "Lindo Cerro Colorado", "No me dejes partir, algarrobo", entre muchas otras.

De esta manera, se puede decir que toda su obra fue atravesada por la geografía y la etnografía. Era tan aficionado a la etnografía y a la antropología que en 1949 acompañó al etnólogo francés Alfred Métraux "en sus estudios por la provincia de Salta, estudiando la vida de los chiriguanos, ingresando a Bolivia por Tarija, andando y andando, siempre andando" (GUTIÉRREZ, $\mathrm{s} / \mathrm{d}$ ). Para Yupanqui estas excursiones etnológicas eran cruciales para su creación artística y perfilaron su obra hacia temas telúricos y paisajísticos. Esa vasta experiencia etnográfica duró toda su vida y fue reflejada tanto en sus canciones como en sus libros. En sus 12 libros publicados, es posible apreciar relatos poéticos pertenecientes a la tradición de la literatura oral llamada copla, en los cuales el noroeste andino es el paisaje temático dominante, abordado a partir de componentes de la naturaleza, personajes humanos regionales y lugares. En esta línea, se pueden nombran "Piedra sola: poemas del cerro" (1941), "Aires indios" (1947) y "Guitarra" (1954). Como ejemplo de obra etnográfica se destaca "Cerro Bayo: vida y costumbres montañescas" (1946). Este libro que tiene una estructura de novela es en realidad una suerte de manifiesto "de los caminos y los vientos, un alarido en capítulos de cerros, un volcán de párrafos y silencios". Así el propio Yupanqui avisa en el prefacio dirigido al amigo lector:

Las costumbres y tradiciones expuestas en este libro han sido observadas y cuidadosamente fijadas. No hay en toda la obra juego alguno de imaginación. Desde el detalle de los amaneceres, los ocasos y las noches, las fiestas y las dudas y pesares de los hijos de la sierra, todo responde a la realidad de la vida en Cerro Bayo (1946, p. 5).

Atahualpa Yupanqui "nos invita en esta oración, a comprender que el paisaje es alimento, alimento de los paisajes vivientes, como los caballos, Atahualpa nos invita a una discusión de paisajes: ¿Cuál es el paisaje de quién? ¿Quién es el paisaje de qué?". De esta manera, el paisaje y sus elementos siempre resultaron evocadores para Yupanqui, tanto para traer la poesía

9 Resumen y sinopsis de Cerro Bayo en Lecturalia. Disponible en: http://www. lecturalia.com/libro/97176/cerro-bayo. Acceso en: 23 feb. 2019. 
a sus composiciones como para conectarse con la ancestralidad de las personas que habitaron las mismas tierras que él pisó.

\section{Territorio y Música: un dialogo, múltiples ecos}

Partiendo del entendimiento de que la identidad de un territorio (HAESBAERT, 1999, 1997) se construye de forma dialéctica entre el ser humano y el espacio geográfico, y que los espacios despiertan diferentes tipos de reacciones en las personas (TUAN, 2012, 2006), se cree posible hablar que las geografías contienen en sí mismas particularidades que pueden ser expresadas a través de sonidos, ruidos, tonalidades, acústicas, imágenes, notas (DOZENA, 2019a). Esas grafías que el espacio posee, al ser abordadas e interpretadas por el ser humano se tornan, indefectiblemente, obras de arte que por definición son subjetivas y a su vez, poseen el potencial de convertirse también en colectivas. Por eso, se entiende que los sonidos son una fuente de conocimiento como pueden ser un libro o una película. En este sentido, comparto la idea de que: "Los sonidos de nuestro entorno [...] establecen vínculos invisibles. Ciertos sonidos en nuestra memoria nos vinculan al territorio, a los recuerdos, a nuestro inconsciente, siendo así que todo ruido y sonido del entorno natural o artificial, configuran el paisaje sonoro" (CARTOGRAFÍA SONORA DE LA ARAUCANÍA, 2013).

Aquí se desprende la idea de paisaje sonoro mediante la cual nos permite reflexionar sobre las cuatro obras de arte presentadas en este trabajo. En mayor o menor medida las cuatro obras pueden ser analizadas por medio de este concepto acuñado por el compositor y educador canadiense Raymond Murray Schafer. Si bien en el libro The Soundscape: our sonic environment and the tuning of the world (1977) Schafer se centró en el estudio de los paisajes sonoros de las ciudades, o sea, espacios urbanos, esto no impide que el concepto pueda ser ampliado y contemplar también ambientes más rurales o menos urbanizados. Con este libro se dio inicio a un movimiento que buscaba percibir el medio ambiente sonoro en el cual el ser humano estaba inserido, haciéndolo responsable también por la composición paisajística. Así, el autor creó el término 'paisaje sonoro' para denominar el conjunto de sonidos provenientes de un espacio determinado, en estrecha relación con el entorno social en el cual se producen y también revelan el grado de evolución del grupo social y del espacio que ocupa (Ibídem). Lo más interesante de ese trabajo fue que demostró la manera en la cual los sonidos son responsables por una caracterización peculiar de determinados ambientes acústicos $y$, en consecuencia, por la impregnación de sonidos del lugar. Según Schafer, el paisaje sonoro está compuesto por tres elementos: tonalidades, señales sonoras y marcas sonoras. Respecto esta última, el autor sostiene que:

El término marca de sonido deriva de marca terrestre y se refiere a un sonido de comunidad que es único o posee cualidades que lo hacen especialmente considerado u observado por las personas de esa comunidad. Una vez que una marca de sonido ha sido identificada, merece ser protegida, ya que las marcas de sonido hacen que la vida acústica de la comunidad sea única (1977, p. 10).

A este respecto, Cárdenas-Soler y Martínez-Chaparro agregan que estas marcas de sonido "se refieren a los sonidos (con valor simbólico y afectivo) que describen con mayor fidelidad las cualidades socioculturales de una comunidad" (2015, p. 132).

De esta manera, se entiende que el artista se expresa mediante su arte a partir de lo que percibe e intuye que está contenido en el territorio en el cual se encuentra. Este movimiento genera diálogos entre la música y el espacio que se desdoblan en múltiples sentidos que quedan plasmados en las obras musicales aquí analizadas, así como también en todas las manifestaciones artísticas. Siguiendo con esta idea, el caso de Sincronicidad Astral con su álbum "Piedras de plata" (2016) procura establecer un diálogo directo con el paisaje, ya que utilizan registros grabados del ambiente natural (FARRELL, 2016) de la localidad de Cerro Colorado. Lo que se busca aquí es un fiel registro de la sonoridad del paisaje para poder incorporarlo a sus composiciones. De este modo, ellos conciben las tonalidades y sonoridades del paisaje como material sonoro para su música, o, mejor dicho, como material inspirador a partir del cual crear. Queda claro que la intención de establecer un diálogo directo con el territorio estaba pautada desde el inicio y fue así que buscaron captar de la forma más explícita y fidedigna posible las marcas sonoras que la comunidad posee con el objetivo de poder reproducirlas como fondo melódico/ sonoro de sus canciones. Así, los miembros de la banda dejan entrever que creen en la conexión con la tierra y comparten la creencia de que ésta es una fuente inagotable de inspiración y energía primordial a la cual se debe respetar, reverenciar y rendir homenaje.

Tal vez el caso de Pompeya por parte de la banda Pink Floyd sea el que menos se ajuste a esta idea de paisaje sonoro esbozada aquí y, por lo tanto, planteé otras perspectivas para analizar este diálogo entre música y territorio. Como ya se mencionó en el apartado dos, la inspiración para realizar el documental provenía de la historia del lugar y la acústica que el anfiteatro podía 
llegar a producir en una grabación en vivo. Es sabido que estos lugares eran pensados en función de la acústica que podrían llegar a tener para facilitar que la voz de los actores que estuviesen representando llegase a todos los lugares de la platea. En este sentido, el anfiteatro romano de Pompeya poseía todas las características acústicas (RODRÍGUEZ, 1998) y simbólicas que tanto los integrantes de la banda como el director del documental querían darle a este registro audiovisual. Es decir, deseaban que las canciones seleccionadas fuesen grabadas en este espacio porque, de alguna manera, dialogaban con este lugar y también porque este ambiente le otorgaba a las composiciones una profundidad sonora y dramática singulares. A partir de lo expresado por el director (EASLEA, 2017; FIELDER, 2016), se intuye que este registro audiovisual funcionó como una forma de conexión con los espíritus de las personas que habitaron Pompeya antes de la erupción y que estas músicas podían llegar a articular un diálogo con los fantasmas que quizás aún estaban rondando esa ciudad. Entonces, a pesar de no haber sido una intención declarada por el director ni por la banda, se puede pensar que, a partir de la grabación de las canciones en un espacio como el anfiteatro de Pompeya, daría como resultado un paisaje sonoro muy peculiar y cargado de sensaciones, emociones y sentimientos.

En el caso de la obra "A cidade sonora" de Floriano Romano, si bien se pretendió captar el paisaje sonoro de los diferentes lugares alrededor del mundo, la búsqueda pasaba más por registrar los sonidos de las ciudades tal cual son vistas, escuchadas, sentidas por sus habitantes. Las ciudades que formaron parte de la obra de Floriano Romano buscaron mostrar su cara según la visión sonora de las personas que efectuaban el registro mediante "la interface crucial entre el individuo y el medio ambiente" logrando ser un "camino de intercambio de informaciones" y no tan solo "una reacción auditiva a un estímulo" (Santos, 2002, p. 33, apud FURLANETTO, 2019 , p. 361). Cabe decir que esos registros no tuvieron intención de completitud, es decir, no tenían la pretensión de concebirse como espejo fiel de dicha ciudad, ni tampoco emblemáticos, o sea, que funcionasen como una marca sonora por antonomasia. Todo lo contrario, buscaron mostrar otras ciudades dentro de la misma ciudad, lejos de los lugares más representativos (o turísticos) para poder demostrar que existen múltiples ciudades sonoras imaginarias e imaginadas por cada uno de sus habitantes.

Y para finalizar, en la obra que Atahualpa Yupanqui compuso inspirado en el Cerro Colorado, se puede observar que existió por parte del cantautor argentino un respeto, una cierta voluntad de intentar captar todo lo que allí estaba a la espera de ser escuchado, sentido y mirado, aunque lo invisible, lo que estaba más allá del alcance de la mirada, fuese lo que más le importó a éste artista que dedicó su vida a descifrar los paisajes:

No he compuesto muchas canciones, sí muchos versos, coplas sueltas, pero no así canciones, tal vez, unas 20 o 25 canciones en 40 años dedicadas a este paisaje. Supera en belleza y en misterio mis condiciones de músico o de compositor este lugar de chañares, de garabatos, de viejos algarrobos, de quebrachos blancos, de quebrachos colorados. Supera en belleza y en sugestiones a mis condiciones que no son muy vastas. Hay en mí una orfandad de profundos conocimientos, no así de anhelos, que son infinitos, no así de anhelos (YOUTUBE - LINDO CERRO COLORADO, 1985).

Esta tentativa de convertir el entorno natural en canción, esta capacidad del "sonido de la música de transformarse en el resultado de procesos de comportamiento humano que están moldeados por los valores, actitudes y creencias de las personas que conforman una cultura particular" (MERRIAM, 1964, p. 6), fueron losaspectos que Yupanquipersiguió musicalmente e intentó incorporarlos a sus composiciones.

En resumen, se puede decir que cada una de las obras sonoras y/o musicales buscó, a su manera, un diálogo con el territorio $y$, por lo tanto, es posible manifestar que se presentaron cuatro maneras diferentes de abordar artísticamente - a través del sonido, de los ruidos, de la música - el espacio geográfico. Cada artista con sus recursos e impronta procuró identificar los sonidos de dichos lugares con el objetivo de caracterizarlos y otorgarles una identidad sonora propia. Aunque esto no quiere decir que la identidad sea única para todos los habitantes de un territorio, sí se cree que un determinado porcentaje de dichas características representan y hacen que los lugares sean reconocibles por aspectos que también incluyen lo sonoro. 


\section{Referências}

CALVINO, I. (2003) Las ciudades invisibles. Madrid: Ediciones Siruela.

CÁRDENAS-SOLER, R. N. y MARTÍNEZ-CHAPARRO, D. (2015) El paisaje sonoro, una aproximación teórica desde la semiótica. Revista Investigación, Desarrollo e Innovación n² 2, vol. 5, p. 129-140.

CARNEY, G. O. (2007) Música e Lugar. In: Rosendahl, Z. e Corrêa, R. L. (orgs.). Literatura, Música e Espaço. Rio de Janeiro: EdUERJ.

CARNEY, G. O. (org.) (2003) The Sounds of People and Places: a geography of American music from country to classical and blues to bop. Lanham: Rowman \& Littlefield.

(1993) The Sounds of People and Places: a geography of American folk and popular music. Lanham: Rowman \& Littlefield.

CARTOGRAFÍA SONORA DE LA ARAUCANÍA. (2013) Proyecto de un mapa sonoro de la región de Araucanía llevado a cabo por Cine Puño, Temuco.

DOZENA, A. (2019a) Os sons como linguagens espaciais. Espaço e Cultura nº 45, p. 31-42.

DOZENA, A. (org.). (2019b) Geografia e Música: diálogos. Natal: EdUFRN.

(2012) Territorializações urbanas como práticas de resistência. Terra Plural, v. 6, n. 2, p. 215-228.

(2009) As territorialidades do samba na cidade de São Paulo. 266 f. Tese (Doutorado em Geografia) - Departamento de Geografia da Faculdade de Filosofia, Letras e Ciências Humanas da Universidade de São Paulo, São Paulo.

EASLEA, D. (2017) The inside story of Pink Floyd's classic Live at Pompeii. loudersound.com, s/p. Disponible en: https:// www.loudersound.com/features/the-inside-story-of-pink-floyds-classic-live-at-pompeii. Acceso en: 18 dic. 2018.

ESPINHO, J. E. (2012) A cidade sonora de Floriano Romano. Disponible en: http://umbigomagazine.com/um/2012-0925/a-cidade-sonora-de-floriano-romano-babilonia-afectiva-segredo-utopia.html. Acceso en: 17 dic. 2018.

FARRELL, B. (2016) Music and Nature. ReVista vol. XV, n² 2, p. 2-5.

FIELDER, H. (2016) Pink Floyd's Live at Pompeii: the saga of rock's most epic home movie. loudersound.com, s/p. Disponible en: https://www.loudersound.com/features/pink-floyd-s-live-at-pompeii-the-saga-of-rock-s-most-epic-homemovie. Acceso en: 19 dic. 2018.

FRITH, S. (2003) Music and Identity. In: Hall, S., Du Gay, P. (eds.). Questions of Cultural Identity. London: SAGE Publications. 1996. Performing Rites: on the value of popular music. Harvard: Harvard University Press.

FROBENIUS, L. (1897) Der westafrikanische Kulturkreis. Harvard: Harvard University Press.

FURLANETTO, B. H. (2019) Paisagem sonora: uma composição geomusical. In: Dozena, A. (org.) Geografia e Música: diálogos. Natal: EdUFRN.

GIRONCOURT, G. de. (1939) Recherces de Géographie musicale dans le Sud Tunisien. La Géographie, v. LXXL, n. 6, p. 65-74.

GUTIÉRREZ, M. Á. s/d. BIOGRAFÍA - Atahualpa Yupanqui. Disponible en: http://www.fundacionyupanqui.com.ar/ata-bio. html. Acceso en: 23 feb. 2019.

HAESBAERT, R. (2005) 0 mito da desterritorialização: do 'fim dos territórios' à multiterritorialidade. Rio de Janeiro: Bertrand Brasil.

(1999) Identidades territoriais. In: Rosendahl, Z. e Corrêa, R. L. (orgs.). Manifestações da cultura no espaço. Rio de Janeiro: EdUERJ.

(1997) Território, poesia e identidade. Espaço e Cultura nº 3, p. 20-32.

KONG, L. (1995) Popular music in geographical analysis. Progress in Human Geography n. 19, issue 2, p. 183-198.

LECTURALIA. S/D. Disponible en: http://www.lecturalia.com/libro/97176/cerro-bayo. Acceso en: 23 feb. 2019.

MERRIAM, A. P. (1964) The anthropology of music. Evanston, Illinois: Northwestern University Press.

PANITZ, L. M. (2012) Geografa e música: uma introdução ao tema. Biblio 3W, Revista Bibliográfica de Geografía y Ciencias Sociales $n^{\circ}$ 978, vol. XVII, s/p.

Pink Floyd: Live at Pompeii (documental). Adrian Maben. Inglaterra. 1972. Duración: 60 minutos.

PINK FLOYD: Echoes. Wikipedia - la enciclopedia libre. Disponible en: https://en.wikipedia.org/wiki/Echoes_(Pink_ Floyd_song). Acceso en: 18 dic. 2018.

. A saucerful of secrets. Wikipedia - la enciclopedia libre. Disponible en: https://en.wikipedia.org/wiki/A_Saucerful_ of_Secrets_(instrumental)\#cite_note-10. Acceso en: 18 dic. 2018.

One of these days. Wikipedia - la enciclopedia libre. Disponible en: https://en.wikipedia.org/wiki/One_of_These_

Days_(instrumental). Acceso en: 18 dic. 2018. 
RODRÍGUEZ, Á. L. L. (1998) La acústica de los teatros a través de la historia. Segundo Congreso Nacional de Historia de la construcción, p. 263-272.

ROMANO, F. (2012) "A Cidade Sonora", de Romano, é aberta no Rio. Disponible en: http://www.funarte.gov.br/artesvisuais/"a-cidade-sonora"-de-romano-e-aberta-no-rio/. Acceso en: 19 dic. 2018.

SANTOS, F. C. dos. (2002) Por uma escuta nômade: a música dos sons da rua. São Paulo: EDUC.

SCHAFER, R. M. (1977) The Soundscape: our sonic environment and the tuning of the world. Rochester: Destiny Books. SINCRONICIDAD ASTRAL. Piedras de plata. (2016) Disponible en: https://open.spotify.com/ album/62qpfXgV56KxxBdvmhXRb7. Acceso en: 12 dic. 2018.

Buscando huellas del olvido. (2014) Disponible en: https://www.youtube.com/ watch?v=kT945dGhbzM\&list=OLAK5uy_km5oYIE_uOsgTezkxUV5nfi5hUgg3NfM0. Acceso en: 12 dic. 2018.

SMITH, S. J. (1997) Beyond geography's visible worlds: a cultural politics of music. Progress in Human Geography, California, n. 21, p. 502-529. (1994) Soundscape. Area vol. 26, n.3, p. 232-240.

TUAN, Y-F. (2012) Topofilia - um estudo da percepção: atitudes e valores do meio ambiente. Londrina: Edual. (2006) Paisagens do medo. São Paulo: Unesp.

YOUTUBE-Lindo cerro colorado $1^{\mathrm{a}}$ parte. (1985) Disponible en: https://www.youtube.com/watch?v=0V1-sTrvCXo\&t=65s. Acceso en: 20 dic. 2018.

YUPANQUI, A. (1954) Guitarra: poemas y cantares argentinos. Buenos Aires: Siglo Veinte. (1948) Tierra que anda. Buenos Aires: Editorial Anteo.

(1947) Aires indios. Montevideo: Editorial Letras de Montevideo.

(1946) Cerro Bayo: vida y costumbres montañesas. Buenos Aires: Editorial Problemas.

(1941) Piedra sola: poemas del cerro. Jujuy: Editorial Riba y Compañía. 